\title{
An experimental investigation on metal surface treatment by means of diode laser beams
}

\author{
A. Paoletti \\ Department of Industrial and Information Engineering and Economics, \\ University of L'Aquila, Italy
}

\begin{abstract}
Surface treatment of steel, for a higher wear resistance, is necessary in all industrial branches that deal with steel. One of the most effective methods of metal surface heat treatment is represented by laser hardening. In general, compared to other techniques, laser hardening needs a much lower heat input into the material. Compared with other conventional processes, diode laser treatment allows us to obtain some advantages, such as minimum distortion in the parts and selective hardening of specific areas of components. In this paper, an experimental investigation on the surface thermal treatment of different steels by means of a diode laser has been carried out. Experimental tests have been performed on three types of steels, selecting different values of beam power and workpiece speed. Hardness and micro-hardness measurements have been executed on the treated samples in order to assess the influence of laser machining parameters and of workpiece materials on the treatment process. Experimental results have been compared with those obtained by using a monodimensional thermal model. The morphology of the heat affected zone of the specimens has been investigated by scanning electron microscopy.
\end{abstract}

Keywords: diode laser, surface treatment, surface hardening, laser treatment.

\section{Introduction}

Laser beam energy is used in different technological processes, such as cutting, drilling, welding and heat treatment of a surface layer [1-3]. The advent of Diode Laser (DL) is having significant impact on modern production technology. 
Productivity, cost reduction and quality of materials processing are the main factors driving the actual development of Diode Laser systems [4-6]. If compared with other laser sources, the DL beam is characterised by a higher level of absorption of its radiation and by a higher compactness [7, 8]. At low intensity, the main applications concern hardening, heat conduction welding of metals and joining of polymers. At high beam power, DL technology is utilised in metal working, like welding and cutting. Flexible adaptation to a variety of geometrically different parts, minimised distortion by simultaneous hardening and pyrometric monitoring of the quality are features to these laser systems [9, 10]. Hardening of steel for a higher wear resistance is necessary in all industrial branches that deal with steel, from vehicles to typewriters [11-13]. In general, compared to other hardening methods, laser hardening needs a much lower heat input into the material. This reduces the distortion of the hardened parts and can be an advantage over other hardening technologies. Applications which require low distortion, because no machining or bending process after hardening is allowed, concern piston rings, hardened blades and side-cutting pliers [14]. The hardening depth depends on the properties of the steel and the performance of the laser. The properties of the steel concern its transformation temperatures, thermal conductivity and volumetric specific heat. The performances of the laser include its power, beam size, scan speed, surface absorption and the energy distribution of the beam. The laser beam parameters greatly affect the level and the kinetics of transformation of the parent phase into austenite and on selfcooling leading to transformation of austenite into martensite [15, 16]. For this reason it is necessary to determine suitable parameters of laser beam, selecting their best combination [17-19]. Modelling of laser treatment makes it possible to assess quantitatively the phase composition and the depth of the hardened layer [20]. Applications of numerical simulations allow one to control more precisely the process at the same time making it automatic. On the grounds of numerical simulation results, the effects of laser treatment can be predicted as the function of power density, beam dimensions and time of radiation affecting the steel [21].

In this paper an experimental study on the surface thermal treatment of different steels by means of a diode laser beam has been developed. Different laser machining parameters have been selected.

\section{Experimental set up}

The experimental set up consists of a diode laser head and a CNC linear slide, as shown in Figure 1.

The continuous wave diode laser is able to give a maximum power equal to $1055 \mathrm{~W}$ at $0,94 \pm 0,01 \mu \mathrm{m}$ wavelength. The rectangular beam spot size is equal to $3.6 \mathrm{x} 0.8 \mathrm{~mm}$ and the working distance is equal to $60 \mathrm{~mm}$. The workpiece specimens are parallelepiped shaped 20 × 20 x $90 \mathrm{~mm}$ and have been clamped on the CNC linear slide. Different values of the interaction time have been obtained by varying the scanning speed of the CNC linear slide. The maximum value of the slide is equal to $60 \mathrm{~mm} / \mathrm{s}$. In Table 1 the workpiece materials and the laser machining parameters adopted during tests are reported. 


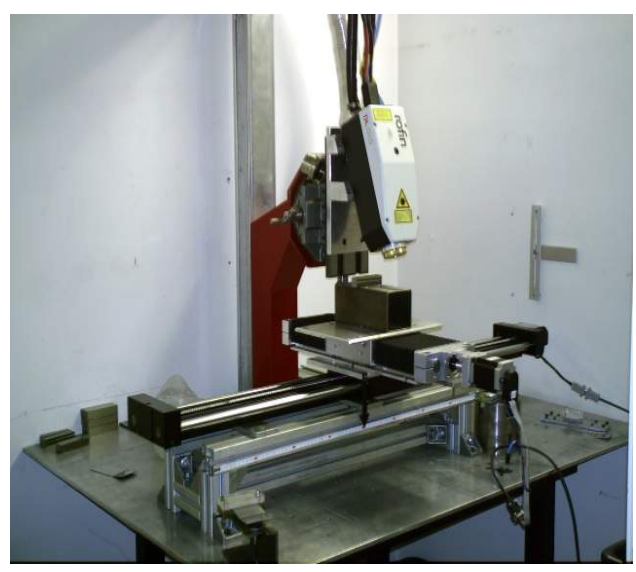

Figure 1: $\quad$ Experimental set up.

Table 1: Workpiece materials and laser machining parameters adopted during experimental tests.

\begin{tabular}{|c|c|c|}
\hline Workpiece materials & Beam power $(\mathrm{W})$ & Workpiece speed $(\mathrm{mm} / \mathrm{s})$ \\
\hline C45; X210Cr13; & $300 ; 500$ & $5 ; 10 ; 14 ; 20 ;$ \\
X150CrMo12 & & $26.5 ; 40 ; 53$ \\
\hline
\end{tabular}

\section{Experimental results and discussion}

Hardness measurements have been carried out both on the treated zones and base metal in order to assess the influence of laser machining parameters and of workpiece materials on the treatment process, as shown in Figure 2. From each specimen a cross-section, having $10 \mathrm{~mm}$ thickness, has been cut and polished. Micro-hardness measurements have been performed at different distances from the surface. Subsequently, the cross-section samples have been chemical etched by means of Nital solution and analysed by scanning electron microscope (SEM). Typical images are shown in Figure 3. Metallographic analysis, carried

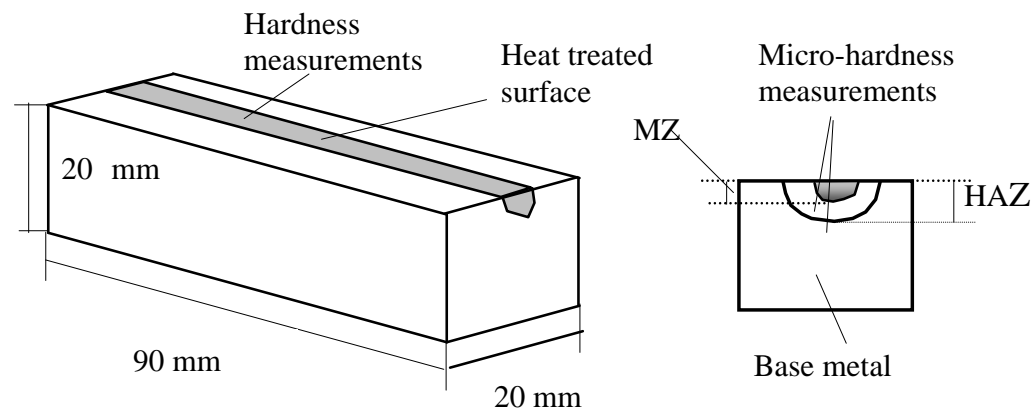

Figure 2: $\quad$ Scheme of workpiece specimen. 


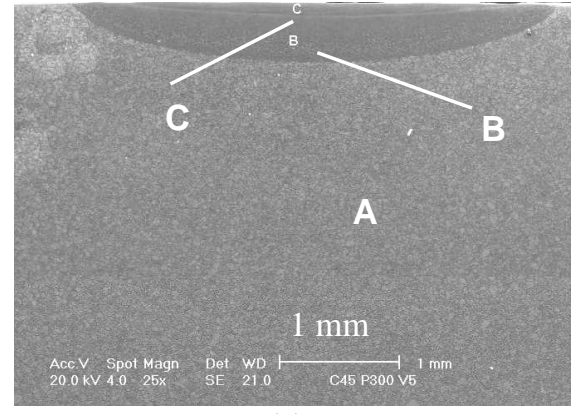

(a)

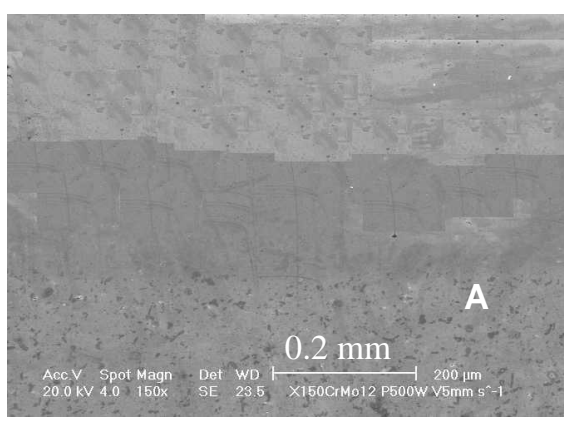

(b)

Figure 3: $\quad$ SEM-micrograph of C45 (a) and X150CrMo12 (b) steel.

out on the cross-section samples, has exhibited the presence of a non heat affected zone (base metal), a heat affected zone (HAZ) and a melted and resolidified zone (MZ). The melted zone is absent when beam power has been lower and/or workpiece speed has been higher than typical values. The presence of the melting zone has caused cracks formation after the re-solidification of the melted metal. The cracks formed in the melted zone, have given rise to an increase of surface roughness of workpiece.

The SEM-micrograph of C45 steel depicted in Figure 3(a), exhibits the base metal structure, which is composed of perlite and pro-eutectoid ferrite (zone denoted by letter A). In the heat affected zone having a depth of about $0.6 \mathrm{~mm}$, the melting zone, designated by letter $\mathrm{C}$, is clearly visible on the edge of the cross section. This melting zone is about $0.10 \mathrm{~mm}$ thick and contains acicular martensite. Under the melting layer, it is observed a heat affected zone that consists of martensite, bainite and pro-eutectoid ferrite structure (denoted with letter B). In steels having a high level of chrome, such as X150CrMo12, the base metal is characterised by the presence of a large amount of carbides particles (the dark particles in the region A shown in Figure 3(b)). On the contrary, carbides are almost absent in the heat affected zone, B.

In Table 2 the boundary values of laser beam power and of workpiece speed, where the metal has not reached the melting point, are reported. The thickness of the melting zone has been also measured.

Table 2: Laser machining parameters and correspondent thickness of melting zone.

\begin{tabular}{|c|c|c|c|}
\hline $\begin{array}{c}\text { Workpiece } \\
\text { material }\end{array}$ & $\begin{array}{c}\text { Laser beam power } \\
(\mathrm{W})\end{array}$ & $\begin{array}{c}\text { Workpiece speed } \\
(\mathrm{mm} / \mathrm{s})\end{array}$ & $\begin{array}{c}\text { Melting zone } \\
\text { thickness }(\mathrm{mm})\end{array}$ \\
\hline \multirow{2}{*}{ C45 } & 300 & 20 & 0.06 \\
\hline & 500 & 26.5 & 0.06 \\
\hline X210Cr13 & 300 & 40 & 0.09 \\
\cline { 2 - 4 } & 500 & 53 & 0.11 \\
\hline X150CrMo12 & 300 & 5 & 0.06 \\
\cline { 2 - 4 } & 500 & 26.5 & 0.06 \\
\hline
\end{tabular}


The lower tendency to reach the melting condition has been yielded for X150CrMo12 steel. In Figure 4 the typical trends of HAZ thickness as a function of workpiece speed for different workpiece materials are reported.

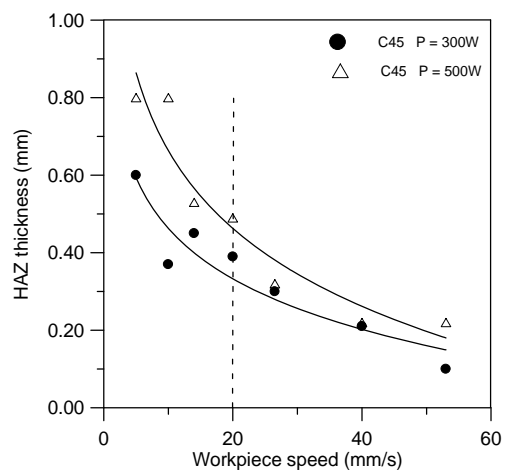

(a)

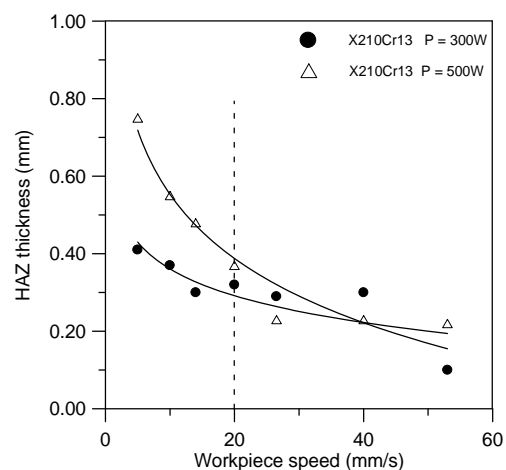

(b)

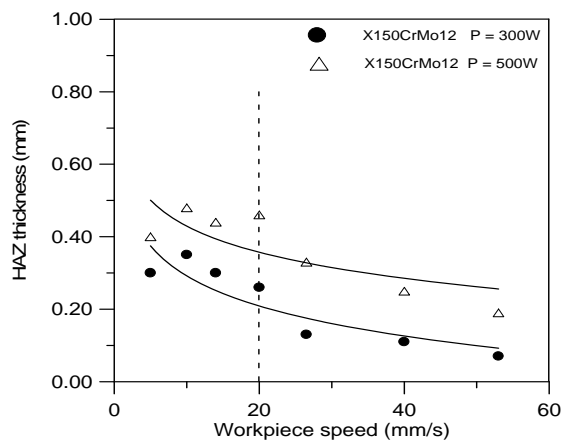

(c)

Figure 4: HAZ thickness as a function of workpiece speed for different steels: C45 (a), X210Cr13 (b), X150CrMo12 (c).

By analysing the experimental data, it is possible to notice that the influence of beam power on the HAZ thickness is less evident than that of workpiece speed. For both values of beam power, the influence of workpiece speed on thickness of heat affected zone is considerable till a boundary value assessed equal to about $20 \mathrm{~mm} / \mathrm{s}$. A mono-dimensional mathematical model has been used to investigate the thermal flow [21]. Under the assumption that the entering flow and the thermal parameters of the material are constant during the whole interaction time and disregarding the latent heat of the structural changes, the HAZ thickness has been assessed. Figure 5 reports a comparison between experimental and model values of HAZ thickness as a function of workpiece speed for X210Cr13 steel.

A good correlation between theoretical and experimental data has been obtained; in particular, model values interpolate very well experimental values, when a beam power value equal to $500 \mathrm{~W}$ has been used (Figure 5(b)). 


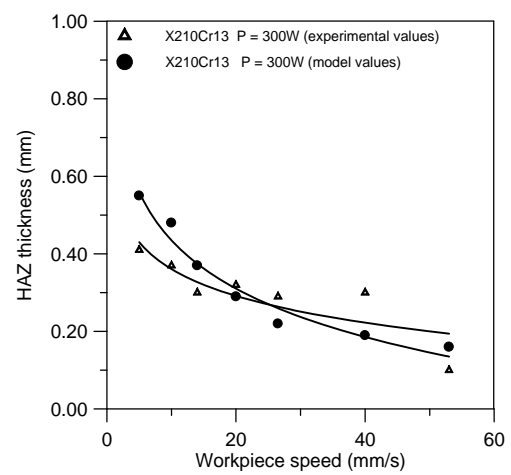

(a)

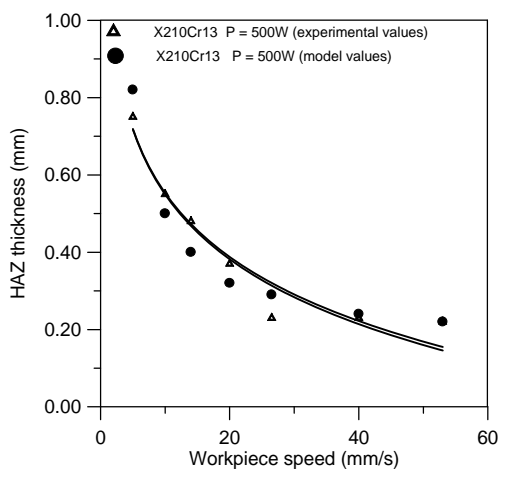

(b)

Figure 5: Experimental and model values of HAZ thickness as a function of workpiece speed for X210Cr13 steel.

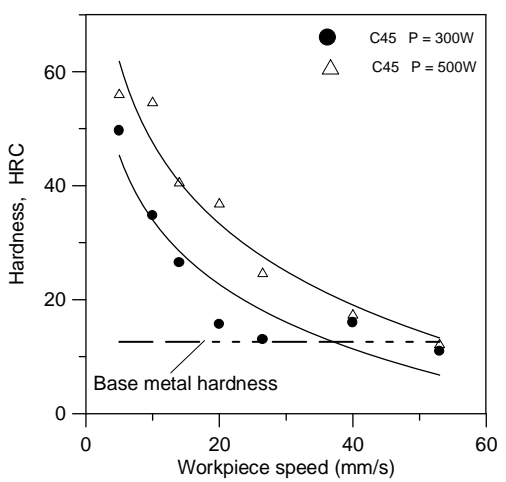

(a)

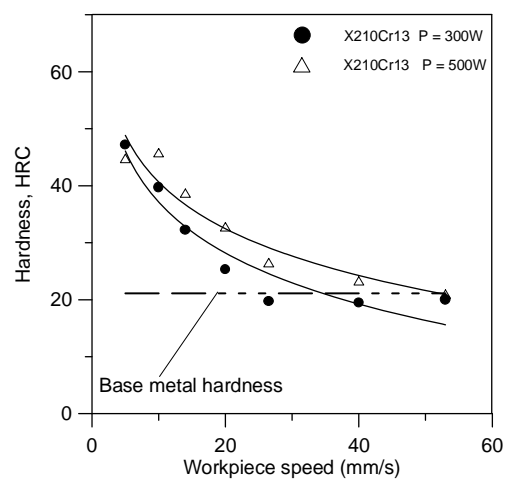

(b)

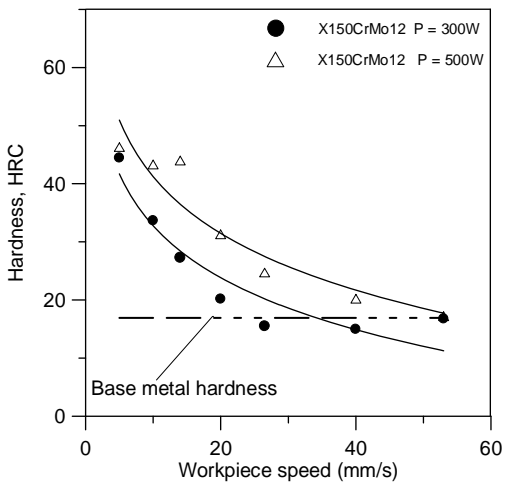

(c)

Figure 6: Workpiece hardness as a function of workpiece speed for different steels: C45 (a), X210Cr13 (b), X150CrMo12 (c).

Figure 6 shows the typical trends of workpiece hardness as a function of workpiece speed. Hardness measurements have been carried out on the workpiece surface, which has been treated by laser beam (see Figure 2). 
Concerning the laser machining parameters, metal hardening has been much more dependent on workpiece speed rather than beam power. For workpiece speed higher than $26.5 \mathrm{~mm} / \mathrm{s}$, the heat treatment has not produced hardening of material.

Figure 7 shows the trend of micro-hardness as a function of depth for C45 steel. The measurements have been carried out at different distances from the surface, on the cross-section of the treated specimens (as indicated in Figure 2).

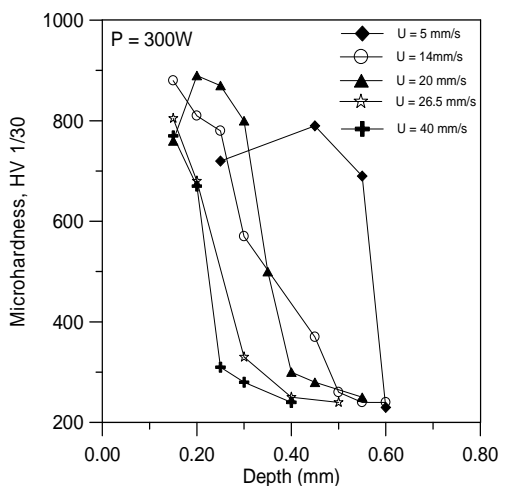

(a)

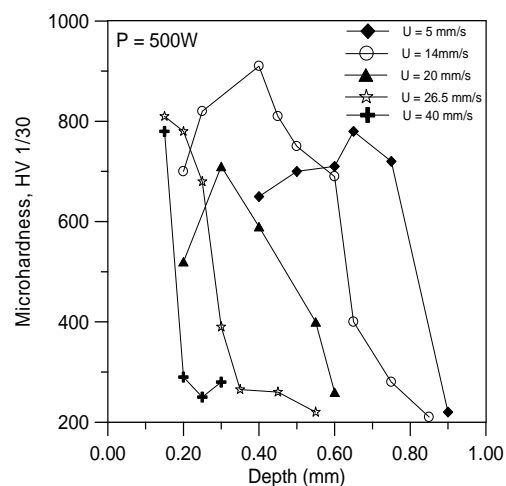

(b)

Figure 7: Workpiece micro-hardness as a function of depth for C45 specimens. (Measurements have been carried out in the heat affected zone.)

As can be seen, the micro-hardness decreases moving from the surface to the inner layers of material, but not following a monotonous law. In fact, the maximum value of the micro-hardness has been reached not on the surface, but in correspondence of a typical value of the distance from the surface. This value is dependent on the laser machining parameters. It increases when higher beam powers and lower workpiece speeds have been adopted. This behaviour can be ascribed to the decarburisation of the metal in proximity of the surface layers. Modifications of workpiece material have been analysed utilizing a characteristic parameter $(\mathrm{Pu})$, which is defined as the ratio between the beam power and the square root of the workpiece speed. Figure 8 shows the trends of the HAZ thickness and the HRC hardness as a function of Pu parameter.

The experimental data can be interpolated by a linear law, notwithstanding the scattering is not negligible. In Table 3 the regression equations concerning the thickness of HAZ and the hardness values (HRC), have been calculated for the workpiece materials.

The empirical models shown in Table 3 can be used to determine the value of the ratio between the beam power and the square root of the workpiece speed, in order to obtain a prefixed hardness and a prefixed value of hardened thickness. 


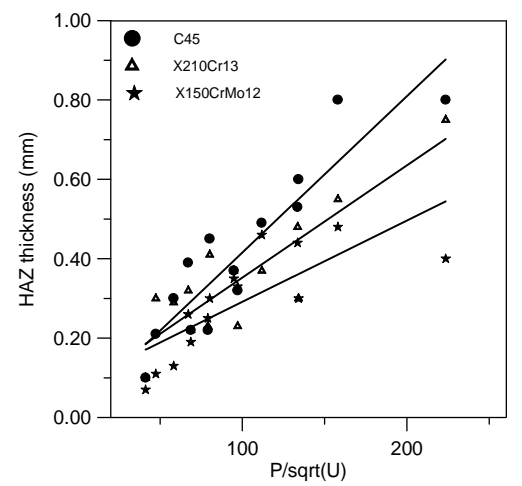

(a)

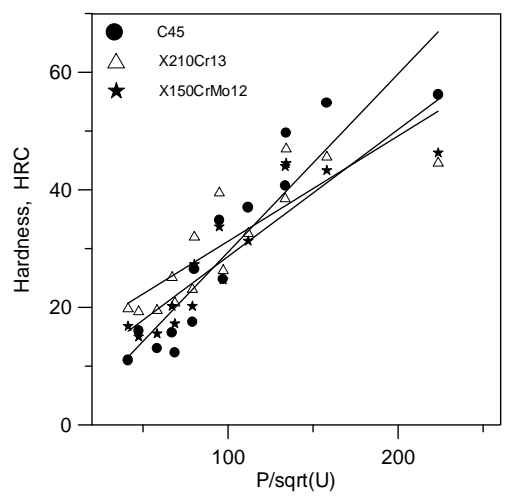

(b)

Figure 8: HAZ thickness (a) and HRC hardness (b) as a function of $\mathrm{Pu}$ parameter.

Table 3: $\quad$ Regression equations for different steels.

\begin{tabular}{|c|l|}
\hline Workpiece material & Regression equations \\
\hline \multirow{2}{*}{ C45 } & HAZ $=0.004 * \mathrm{Pu}+0.022$ \\
& HRC $=0.303 * \mathrm{Pu}+0.94$ \\
\hline \multirow{2}{*}{ X210Cr13 } & HAZ $=0.003 * \mathrm{Pu}+0.070$ \\
& HRC $=0.179 * \mathrm{Pu}+13.3$ \\
\hline \multirow{2}{*}{ X150CrMo12 } & HAZ $=0.002 * \mathrm{Pu}+0.087$ \\
& HRC $=0.216 * \mathrm{Pu}+7.04$ \\
\hline
\end{tabular}

\section{Conclusions}

The thermal treatment of steels by means of a diode laser beam has been investigated. Both processing conditions in which surface melting is present or absent, have been analysed. Boundary values of the laser beam power and of the workpiece speed, where the metal has not reached the melting point, have been found. Hardness measurements have been carried out on the workpiece surface, which has been treated by laser beam. The thickness of the heat affected zone and the micro-hardness have been measured on the cross-section of the treated specimens. It has been found that the interaction time has a greater influence on the thickness of the heat affected zone compared to the beam power. The microhardness decreases from the surface to the inner layers of material, but not following a monotonous relation. In fact, the maximum value of the microhardness has been reached not on the surface, but in correspondence of a typical value of the distance from the surface. This value is dependent on the laser processing parameters. Empirical models may relate the thickness of the heat affected zone and the metal hardness with the ratio of beam power to the square root of workpiece speed. 


\section{References}

[1] Kawasumi, H., Metal surface hardening $\mathrm{CO}_{2}$ laser. Source Book on Applications of the Laser in Metalworking, ASM Engineering Bookshelf, pp.185-194, 1981.

[2] Ehlers, B., Herfurth, H.J. and Heinemann, S., Hardening and welding with high power diode lasers. Proceedings of SPIE, Vol. 3945, pp. 63-70, 2000.

[3] Tani, G., Fortunato, A., Ascari, A. and Campana G., Laser surface hardening of martensitic stainless steel hollow parts. CIRP Annals Manufacturing Technology, 59, pp. 207-210, 2010.

[4] Pashby, I.R., Barnes, S. and Bryden, B.G., Surface hardening of steel using a high power diode laser. Journal of Materials Processing Technology, 139, pp. 585-588, 2003.

[5] Klocke, F., Demmer, A. and Saboklicki A., An investigation into the use of HPDL for hardening and thermal conduction welding for metals. Lasers Materials Process, 30, pp. 592-599, 1997.

[6] Loosen, P., Treusch, G., Haas, C.R., Gardenier, U., Weck, M. and Sinnhoff V., High power diodes lasers and their direct industrial applications. Proceedings of SPIE, Vol. 2382, pp. 78-88, 1995.

[7] Lin L., The advances characteristics of high power diode laser materials processing. Optics and Lasers in Engineering, 34, pp. 231-253, 2000.

[8] Bacham, F.G., High power diode lasers for materials processing: actual status and future aspects. Proceedings of APIE, vol. 4, pp. 157-166, 2001.

[9] Schulz, W. and Poprawe, R., Manufacturing with novel high power diode lasers. IEEE Journal of Selected Topics in Quantum Electronics, 20, pp. 100-109, 2000.

[10] Chen, W., Roychoudury, C.S. and Banas, C.M., Design approaches for laser diode material processing systems using fibres and microoptics. Optics and Laser Engineering, 33 (11), pp. 3662-3669, 1994.

[11] Bonss, S., Brenner, B., Beyer, E. and Bachmann F., Diode laser applications hardening and welding. ICALEO 98 Proceedings, Vol. 85G, Laser Institute of America, pp.121-130, 1998.

[12] Jiang, J., Xue, L. and Wang, S., Discrete laser spot transformation hardening of AISI O1 tool steel using pulsed Nd:YAG laser. Surface \& Coatings Technology, 205, pp. 5156-5164, 2011.

[13] Badkar, B.S., Pandey, K.S. and Buvanashekaran, G., Parameter optimization of laser transformation hardening by using Taguchi method and utility concept. International Journal of Advanced Manufacturing Technology, 52, pp. 1067-1077, DOI 10.1007/s00170-010-2787-z, 2011.

[14] Roth, M. and Cantello, M., Laser hardening of a 12\% Cr steel. Proceedings of the $2^{\text {nd }}$ International Conference on Laser in Manufacturing, Birmingham, pp. 119-128, 1985.

[15] Coutouly, J.F., Deprez, P. and Defontaine, A., Improvements to laser beam characteristics for transformation hardening and surface melting treatments. Lasers in Engineering, 6, pp. 189-202, 1997.

[16] Soriano, C., Leunda, J., Lambarri, J., García Navas, V. and Sanz, C., Effect of laser surface hardening on the microstructure, hardness and residual 
stresses of austempered ductile iron grades. Applied Surface Science, 257 pp. 7101-7106, 2011.

[17] Schneider, D., Hofmann, R. Schwarz, T., Grosser, T. and Hensel, E., Evaluating surface hardened steels by laser-acoustics. Surface \& Coatings Technology, 206, pp. 2079-2088, 2012.

[18] Martínez, S., Lamikiz, A., Tabernero, I. and Ukar, E., Laser hardening process with 2D scanning optics. Physics Procedia, 39, pp. 309-317, 2012.

[19] Mahmoudi, B., Torkamany, M.J., Sabour, A.R., Aghdam, R. and Sabbaghzade, J., Laser surface hardening of AISI 420 stainless steel treated by pulsed Nd:YAG laser. Materials and Design, 31, pp. 2553-2560, 2010.

[20] Santhanakrishnan, S. and Kovacevic, R., Hardness prediction in multi-pass direct diode laser heat treatment by on-line surface temperature monitoring. Journal of Materials Processing Technology, 212, pp. 2261-2271, 2012.

[21] Bokota, A. and Iskierka, S., Numerical prediction of the hardened zone in laser treatment of carbon steel. Acta Material, 44 (2), pp. 445-450, 1996. 